\title{
Immune response mechanisms against Pseudomonas aeruginosa associated with mucosal immunization with protein antigens in a rat model of acute lung infection
}

Linda D. Thomas ${ }^{1}$, Allan W Cripps ${ }^{2 \star}$, Jennelle M. Kyd ${ }^{3}$

Medical School, Australian National University, Canberra, ACT, 2601, Australia ${ }^{1}$.

Griffith Health, Gold Coast campus, Griffith University, Qld, 4222, Australia, ${ }^{2}$

Capricorn Centre for Mucosal Immunology, CQUniversity, Rockhampton, Qld, 4701, Australia. ${ }^{3}$.

Running title: Mucosal immunization against Pseudomonas aeruginosa

Key words: Pseudomonas aeruginosa, immunization, protein antigen, lung, immune response

*Corresponding Author: Allan W Cripps

Griffith Health

Griffith Centre for Medicine and Oral Health

Gold Coast Campus

Griffith University

Queensland 4222

Australia

Tel: +61 756780711

Fax: +61 756780795

Email: allan.cripps@griffith.edu.au 


\section{ABSTRACT}

Pseudomonas aeruginosa is a major cause of nosocomal and community acquired chronic infections in subjects with compromised respiratory function. The microbe is environmentally ubiquitious and has a high level of innate antimicrobial resistance. This has led researchers to investigate vaccine and immunotherapeutic approaches to prevent and treat $P$. aeruginosa infections. Seven cytosolic non-integral proteins were studied as vaccine candidates in an acute lung infection model in the rat. Five of these (amidase, amidopeptidase, KatE, KatE and Pa13 a novel $13 \mathrm{kDa}$ protein) enhanced bacterial clearance from the lung compared to control animals following challenge and are worthy of further study. Immune mechanisms stimulated by these proteins in response to both immunization and infection varied. The most pronounced degree of bacterial clearance from the lung was associated with antigens, which demonstrated greater surface exposure and induced an increase in phagocyte recruitment, in particular, an increased proportion of polymorphonuclear leukocytes. Lymphocytic proliferation and specific antibody responses in the absence of enhanced clearance were less informative as immune correlates. 


\section{Introduction}

Pseudomonas aeruginosa, a Gram-negative opportunistic bacterium, plays an important role in human infections, causing severe complications in burns, major surgery or organ transplant patients [1]. In patients with cystic fibrosis, $P$ aeruginosa is recognized as the principal cause of morbidity and mortality [2]. Immunoprophylaxis and/or immunotherapy may be an effective method for controlling $P$. aeruginosa infections, and for this reason the development of a vaccine has become a priority. Essential to this end is the identification of protective antigens suitable as vaccine candidates. There have been several reviews recently which examine the range of vaccine approaches that are currently been pursued [3-5].

Previous investigations in our laboratory have demonstrated the potential of mucosal immunization with cytosol derived proteins to protect against $P$. aeruginosa infection in a rat model of acute respiratory infection [6, 7].

The use of non-integral outer membrane proteins as vaccine candidates have had precedence in Helicobacter pylori studies, where it has been suggested that these may ultimately be secreted or externalised through lysis of the bacteria [8-13]. In addition, externalisation of cytosolic or periplasmic proteins in Gram negative bacteria may occur through specific transporter mechanisms or through the formation of micro-vesicles [14-19].

In this paper we build on our previous research into non-integral proteins as protective antigens against $P$ aeruginosa in a rodent model of acute lung infection. We have also investigated the contribution of innate and acquired immune responses to the enhanced bacterial clearance that were observed following lung challenge with live organisms.

\section{Methods}

\subsection{Bacteria}


The mucoid P. aeruginosa isolate used for this study, strain 385 (Serotype 2; phagetype 21/44/109/110X/1214) (Pa385), has been studied previously and was originally isolated from a chronically infected cystic fibrosis patient $[7,20]$.

\subsection{Protein Purification}

Seven proteins were purified from Pa385 as previously described [6, 7]. The proteins were identified as azurin, acyl carrier protein (ACP), amidase, amidopeptidase, catalase E (KatE) and catalase A (KatA). One protein with a molecular weight of $13 \mathrm{kDa}$ was considered a novel protein and assigned an identification as Pa13. Possible LPS contamination in protein preparations was assessed by the E-toxate Limulus lysate test (Sigma, St. Louis, MO, USA) (detection limit 0.015 endotoxin untis/ml). No detectable levels of endotoxin were measured in any of the protein preparations.

\subsection{Immunization and Bacterial Challenge}

All animal experiments were conducted with the approval of the institutional animal care and ethics committee. Specific Pathogen Free (SPF) Dark agouti (DA) male rats aged between 8 and 10 weeks were maintained and prepared for immunization as previously described [7]. Animals were immunized sub-serosally under anaesthesia into Peyer's patch (IPP) on day 0. This was followed by an intratracheal boost on day 14 and live challenge on day 21, as previously described [7]. Immunization dosages are detailed in Table 1. Doses varied due to the availability of purified native protein. Animals were sacrificed 4 hours post challenge and bronchoalveolar lavage (BAL) and lung tissue and blood were collected. BAL and lung tissue were prepared for bacterial culture as previously described [6]. Serum was prepared from blood.

\subsection{Preparation of BAL for cell counts}

Cytospin slides were prepared to determine percentages of polymorphonuclear leukocytes (PMNs), macrophages and other cells present in the BAL fluid. A 100ul aliquot of BAL fluid was 
spun for $10 \mathrm{~min}$. at $4.5 \mathrm{x} \mathrm{g}$ onto a microscopic slide using a cytospin apparatus (Shandon Inc. Pittsburgh, Pa, USA). The slides were fixed and stained in Diff Quick (Veterinary Medical Surgical Supply Pty Ltd, Maryville, NSW, Australia), and percentages were determined from three differential cell counts on each slide. Mean percentages \pm the standard error, were calculated from the collected group data.

\subsection{Antigen-specific lymphocyte proliferation assay for ACP and KatA}

Antigen-specific lymphocyte proliferation proliferation for ACP and KatA were conducted on lymhocytes obtained from the mesenteric lymph nodes (MLN) and cultured as previously described [7]. Lymphocyte proliferation was estimated by determining $\left[{ }^{3} \mathrm{H}\right]$ thymidine (Amersham Australia, Nth Ryde, NSW, Australia) incorporation over the last 8 hours of a 4-day culture. Results were calculated by subtraction of the background radioactivity from the geometric means of triplicate assay wells per individual rat lymphocytes and then from this value of the geometric means and the standard error of the entire treatment group were calculated. A $1 \mu \mathrm{g} / \mathrm{ml}$ concentration of purified ACP or KatA, or a $5 \mu \mathrm{g} / \mathrm{ml}$ concentration of ConA (Concanavalin A, Sigma, St Louis, USA) as a mitogenic control, were used for lymphocytic stimulation. The stimulation index was calculated

\subsection{Flow Cytometry}

Pa385 was grown to mid logarithmic phase in nutrient broth [7], and incubated in either nonimmune serum or Pa13, azurine, ACP, amidase, aminopeptidase, KatA or KatE immunized serum at a 1:50 dilution followed by incubation in fluorescein conjugated anti-rat IgG. A total of 20,000 cells were counted and data acquired in the instrument status of logarithmic mode for forward scatter, side scatter and fluorescence.

\subsection{Antigen-specific ELISA for IgA and IgG antibodies against ACP and Catalase A}


Polysorb microtitre wells (Nunc, Roskilde, Denmark) were coated with $1 \mu$ g of purified ACP or KatA in $1 \mathrm{ml}$ of coating buffer. The methodology and mean ELISA titres were calculated as previously described [7].

\section{$2.8 \quad$ Statistical analysis}

Data were expressed as the mean and standard error of the mean. Statistical significance between groups was evaluated using one way analysis of variance or independent $t$ tests. All analyses were carried out using WINKS 4.5 statistics program by Texasoft.

\section{Results}

\subsection{Effects of immunization on pulmonary clearance from the BAL and lung tissue}

The bacterial recovery from the BAL and lung are presented in Fig.1. Animals immunized with amidase, amidopeptidase and KatE showed significant $(\mathrm{p}<0.01)$ clearance of bacteria in the BAL when compared with non-immunized controls. Clearance from the lung tissue from the groups immunized with these proteins was also significant $(\mathrm{p}<0.05)$. The clearance of bacteria from both the BAL and lung tissue of animals immunized with Pa13 and KatA was significantly enhanced compared to non-immunized controls $(\mathrm{p}<0.05)$ Immunization with either azurin or APC did not enhance bacterial clearance from either the BAL or lung tissue

\subsection{Recruitment of phagocytic cells}

The total cell count and differential cell proportions are presented in Table 2. The total number of cells present in the BAL four hours post-challenge was significantly higher than the corresponding controls for Pa13 ( $\mathrm{p}<0.05)$, KatE $(\mathrm{p}<0.05)$ and KatA $(\mathrm{p}<0.01)$. Overall, lung challenge of immunized animals with live bacteria tended to increase the proportion of PMNs in the cell count 
with the exception of azurin where no increase was observed. This increase was significant for Pa13 $(\mathrm{p}<0.01)$ KatE $(\mathrm{p}<0.01)$ and KatA $(\mathrm{p}<0.05)$

\subsection{Antigen-specific cell surface reactivity}

The presence of antigens on the bacterial surface was assessed using flow cytometry and is shown in Fig. 2. Azurin, ACP, amidase, amidopetidase, KatE and KatA were all detected on surface of Pa385 as demonstrated by a shift of the curve to the right when the bacteria where incubated with immune serum. In contrast to ACP, amidase, amidopeptidase, KatE and KatA, the relative curve shift for azurin suggested that it was the least abundant of these proteins on the bacterial cell surface. No appreciable surface reactivity could be demonstrated for Pa13.

\subsection{Antibody responses to ACP and KatA following immunization}

Antibody levels detected in the BAL and serum against ACP and KatA are presented in Fig.3. Significant levels of ACP-specific IgG were detected in both BAL $(\mathrm{p}<0.05)$ and sera $(\mathrm{p}<0.01)$, as well as significant levels of anti-ACP IgA $(\mathrm{p}<0.05)$ in both BAL and sera.

KatA immunization resulted in significant levels of anti-KatA IgG $(\mathrm{p}<0.05)$ in both BAL and sera, however, significant levels of KatA-specific IgA were only observed in the BAL $(\mathrm{p}<0.05)$.

\subsection{ACP and KatA specific lymphocyte proliferation following immunization}

The lymphocyte stimulation indexes for ACP and KatA are shown in Fig.4. Lymphocytes from rats immunized with ACP showed a significant proliferative response compared with the nonimmune control group $(\mathrm{p}<0.01)$ Similarly the KatA immunized animals also showed a significant proliferative response when compared against their respective control group $(\mathrm{p}<0.001)$. A direct 
comparison of the degree of stimulation for these antigens showed an approximate five-fold greater response for KatA compared with ACP.

\section{Discussion}

The mucosal immunization regimen of intestinal priming followed by a pulmonary boost has been found to very useful in identifying potential vaccine antigens against a number of respiratory pathogens $[6,7,21-23]$. Our studies on $P$. aeruginosa have demonstrated that immunization with any one of 5 non-integral OMPs induces enhanced clearance of $P$. aeruginosa from the lungs following challenge with live bacteria. These proteins have been identified as amidase, amidopeptidase, KatE, KatA and Pa13 (a novel 13 kDa protein).

Studies of mucosal immunization with killed whole cell preparations of $P$. aeruginosa have been shown to induce protective immunity and the immune mechanisms described have predominantly been cell-mediated [24-26]. These protective responses are induced by CD4-T cells through T-cell derived cytokines, activation of macrophages, and subsequent recruitment and activation of PMNs. Macrophages play an important role in regulating PMN recruitment through the release of pro- and anti-inflammatory cytokines [27-30]. Saba [31] found that epithelial cells responding to pathogens, also produced cytokines and chemokines involved in recruiting PMNs. This response was found to be excessive in patients with cystic fibrosis and could contribute, in part, to the excessive tissue damage that occurs these patients during an infection episode. In the present study, the 5 antigens (amidase, amidopeptidase, KatE, KatA and Pa13) which induced significant clearance of live bacteria from the lungs of acutely infected animals showed an overall trend to have a greater number of total white cells as well as a greater proportion of PMNs in their BAL. Both the proportion of PMNs and the total cell counts were significantly greater than that observed in the unimmunized controls for 3 of the 5 proteins (KatE, KatA and Pa13). Hence, the early recruitment of PMNs to the lungs at the onset of infection with P.aeruginosa was clearly an 
important mechanism induced through immunization for protection against the initial infection and potentially eventual colonization. The proportion of macrophages recruited to the lungs following live bacterial challenge did not seem to be greatly affected by immunization, although, the relative proportion of macrophages in animals that were immunized with KatA was smaller because the number of PMNs was significantly higher than in other groups . Studies by Buret and coworkers [32] using $P$. aeruginosa whole killed cell immunization, found significantly increased macrophage numbers and activation in protected animals at four hours post challenge. A study of the nontypable Haemophilus influenzae OMP antigen P6, in the same experimental model found no differences in the proportion of PMNs or macrophages between immune and non-immune animals but did demonstrate increased total numbers of white cells in the BAL of animals that received an IT booster immunization [33]. From these studies and our previous work it is clear that different antigens when administered mucosally are capable of enhancing bacterial clearance from the lungs by a number of mechanisms and the effector immune mechanisms may differ between antigens and microbes.

Enhanced pulmonary clearance of $P$. aeruginosa has been reported following adoptive transfer of CD4+ T cells from immunized to naive rats. This protection was antigen specific and occurred in the absence of antibody in either serum or BAL [24, 34]. In this study in vitro lymphocyte proliferation of KatA and ACP was examined. Immunization with KatA induced significant clearance of bacteria from the lung compared to control animals whilst ACP did not. Whilst a significant proliferation response was observed for both proteins the degree of stimulation for KatA was approximately five-fold greater compared with ACP. Further studies are required to determine if there is a threshold proliferative response needed before T cells are able to drive cellular responses in the lung over and above that required for memory. 
Antibody responses are and important component of the immune response in the lung to $P$. aeruginosa. It has been previously demonstrated that levels of antibody correlate with the clearance of $P$. aeruginosa following mucosal immunization [7, 35, 36]. The functional nature of this correlation is supported by studies where passive immunization using either purified IgG [37] or immune sera [34] conferred protection in this rat model of acute respiratory infection. The present study suggests that cell surface reactivity of an antigen is not always indicative of protection. Immunization with Pa13 resulted in significant bacterial clearance and was associated with significant phagocytic recruitment to the lung, however, flow cytometry analysis suggests that this antigen was not surface exposed. Whilst the flow cytometry data suggests that ACP is present on the bacterial cell surface, immunization with this protein did not significantly enhance bacterial clearance. Therefore, cell surface reactivity was not a guarantee for inducing a protective immune response. Comparison of both the ELISA and flow cytometry results indicate that ACP was less immunogenic than KatA.

Until recently, it was assumed that the most favorable antibody responses for vaccine efficacy would be generated against integral outer membrane antigenic structures. It has become clear that a number of non-integral cytosolic proteins may become absorbed to the bacterial surface. Both urease $[8,11,12]$ and catalase $[9,10,13]$ from Helicobacter pylori have demonstrated protective properties including the production of antibody responses.

The process responsible for the presence of these cytosolic proteins on the bacterial surface is at present unclear. Proposed methods include a spontaneous autolysis [16], specific and selective secretion [14] and micro vesicles [15, 17-19]. Cell surface reactivity has been demonstrated for a number of antigens in this study, all of which are considered to be periplasmically located within the bacteria. 
The development of a vaccine for cystic fibrosis patients against $P$. aeruginosa infection presents a major challenge. Many of the proteins in this study have functional roles, including functions that assist the bacterium to survive in vivo or to inactivate host defence mechanisms. Long-lasting mucosal immunity must be stimulated without the harmful induction of inflammatory responses in the lung. Hence, vaccine candidates will need to be assessed for their ability to strike a balance that is able to clear the infection and prevent harm to the host. Greater understanding of the mechanisms of immunity induced is required. From our studies is it concluded that these mechanisms may well be antigen and microbe specific.

\section{Acknowledgements}

This research was supported by a grant from the National Health and Medical Research Council. We are grateful to Melissa Musicka, Catherine Delahunty, Corrina Oszko, Amanda McCue, Mojca Keglovic and David Bastin, for expert technical assistance. 
Fig. 1. Live bacteria recovered from the BAL and lung tissue of rats immunizeed with protein antigens and challenged pos timmunization with live Pa385. The values presented are means \pm standard error of the mean. Significantly different to non-immune group $\left(\begin{array}{c}\hat{\imath}) \\ \mathrm{p}\end{array}<0.01\right.$ and $(\Delta)$ $\mathrm{p}<0.05$. NI - non-Immune [11]; Pa13: a novel $13 \mathrm{kDa}$ protein [6]; Az - azurin [6] ACP - acyl carrier protein [5]; Ad - amidase [5]; Ap - aminidopeptidase [5]; KatE - catalase E [5]; NI KatA non-immune for the KatA group [10]; KatE - catalase E [5]. Numbers in parentheses indicate the number of animals in each group.

Fig.2. Flow cytometry with antiserum to the various proteins. The vertical axis indicates the events detected and the horizontal axis indicates the level of fluorescence. Peaks marked Curve 1 represents Pa385 assayed with non-immune serum. Peaks marked Curve 2 represent Pa385 incubated with antiserum specific for each protein. NI - non-Immune ; Pa13: a novel 13 kDa protein; Az - azurin; ACP - acyl carrier protein; Ad - amidase; Ap - aminidopeptidase; KatE catalase; NI KatA - non-immune for the KatA group; KatE - catalase E..

Fig. 3. KatA and ACP specific IgG and IgA in the BAL and sera of animals that had been imminised with ACP and KatA. The values shown are the means \pm standard error of the mean for $5-6$ animals in each group. Significantly different to non-immune group (*) $\mathrm{p}<0.01$ and $(* *)$ $\mathrm{p}<0.05$.

Fig. 4. ACP specific and KatA specific lymphocyte proliferation of cells isolated from the mesenteric lymph node of non-immunized rats and rats immunized with ACP and KatA. A $1 \mu \mathrm{g} / \mathrm{ml}$ concentration of ACP or KatA or $5 \mu \mathrm{g} / \mathrm{ml}$ of ConA was used as the stimulating antigen. The values shown are tme means \pm standard error of the mean for triplicate cultures. 


\section{References}

[1] Driscoll JA, Brody SL, Kollef MH. The epidemiology, pathogenesis and treatment of Pseudomonas aeruginosa infections. Drugs 2007;67(3):351-68.

[2] Rosenfeld M, Ramsey BW, Gibson RL. Pseudomonas acquisition in young patients with cystic fibrosis: pathophysiology, diagnosis, and management. Current Opinion in Pulmonary Medicine 2003;9(6):492-7.

[3] Sedlak-Weinstein E, Cripps AW, Kyd JM, Foxwell AR. Pseudomonas aeruginosa: the potential to immunise against infection. Expert Opinion on Biological Therapy 2005;5(7):967-82.

[4] Pier G. Application of vaccine technology to prevention of Pseudomonas aeruginosa infections. Expert Review of Vaccines 2005;4(5):645-56.

[5] Doring G, Pier GB. Vaccines and immunotherapy against Pseudomonas aeruginosa. Vaccine 2008;26(8):1011-24.

[6] Thomas LD, Kyd JM, Bastin DA, Dunkley ML, Cripps AW. Immunisation with non-integral OMPs promotes pulmonary clearance of Pseudomonas aeruginosa. FEMS Immunology \& Medical Microbiology 2003;37(23):155-60.

[7] Thomas LD, Dunkley ML, Moore R, Reynolds S, Bastin DA, Kyd JM, et al. Catalase immunization from Pseudomonas aeruginosa enhances bacterial clearance in the rat lung. Vaccine 2001;19:348-57.

[8] Yang X-L, Liu W-C, Yang W-W, Zhong D, Liu Y-H, Zhang J-D, et al. Oral immunization of mice with vaccine of attenuated Salmonella typhimurium expressing Helicobacter pylori urease B subunit. Biomedical \& Environmental Sciences 2005;18(6):411-8.

[9] Radcliffe FJ, Hazell SL, Kolesnikow T, Doidge C, A.Lee. Catalase, a novel antigen for Helicobacter pylori vaccination. Infection and Immunity 1997;65:4668-74.

[10] Krishnamurthy P, Parlow M, Zitzer JB, Vakil NB, Mobley HL, Levy M, et al. Helicobacter pylori containing only cytoplasmic urease is susceptible to acid. Infection \& Immunity 1998;66(11):5060-6.

[11] Hatzifoti C, Roussel Y, Harris AG, Wren BW, Morrow JW, Bajaj-Elliott M. Mucosal immunization with a urease B DNA vaccine induces innate and cellular immune responses against Helicobacter pylori. Helicobacter 2006;11(2):113-22.

[12] Ferrero RL, Thiberge JM, Kansau I, Wuscher N, Huerre M, Labigne A. The GroES homolog of Helicobacter pylori confers protective immunity against mucosal infection in mice. Proceedings of the National Academy of Sciences of the United States of America 1995;92(14):6499-503.

[13] Chen M, Chen J, Liao W, Zhu S, Yu J, Leung WK, et al. Immunization with attenuated Salmonella typhimurium producing catalase in protection against gastric Helicobacter pylori infection in mice. Helicobacter 2003;8(6):613-25.

[14] Vanet A, Labigne A. Evidence for specific secretion rather than autolysis in the release of some Helicobacter pylori proteins. Infection \& Immunity 1998;66(3):1023-7.

[15] Ramon Rocha MO, Garcia-Gonzalez O, Perez-Mendez A, Ibarra-Caballero J, Perez-Marquez VM, Vaca S, et al. Membrane vesicles released by Avibacterium paragallinarum contain putative virulence factors. FEMS Microbiology Letters 2006;257(1):63-8.

[16] Phadnis SH, Parlow MH, Levy M, Ilver D, Caulkins CM, Connors JB, et al. Surface localization of Helicobacter pylori urease and a heat shock protein homolog requires bacterial autolysis. Infection \& Immunity 1996;64(3):905-12.

[17] Negrete-Abascal E, Garcia RM, Reyes ME, Godinez D, de la Garza M. Membrane vesicles released by Actinobacillus pleuropneumoniae contain proteases and Apx toxins. FEMS Microbiology Letters 2000;191(1):109-13. [18] Ciofu O, Beveridge TJ, Kadurugamuwa J, Walther-Rasmussen J, Hoiby N. Chromosomal beta-lactamase is packaged into membrane vesicles and secreted from Pseudomonas aeruginosa. Journal of Antimicrobial Chemotherapy 2000;45(1):9-13.

[19] Beveridge TJ. Structures of gram-negative cell walls and their derived membrane vesicles. Journal of Bacteriology 1999;181(16):4725-33.

[20] Cripps AW, Dunkley ML, Clancy RL. Mucosal and systemic immunizations with killed Pseudomonas aeruginosa protect against acute respiratory infection in rats. Infection and Immunity 1994;62:1427-36.

[21] Murphy TF, Kyd JM, John A, Kirkham C, Cripps AW. Enhancement of pulmonary clearance of Moraxella (Branhamella) catarrhalis following immunization with outer membrane protein CD in a mouse model. Journal of Infectious Diseases 1998;178(6):1667-75.

[22] Kyd JM, Cripps AW, Novotny LA, Verlant V, Lobet Y, Bakaletz LO. Efficacy of the 26-kilodalton outer membrane protein and two P5 fimbrin derived- immunogens to induce clearance of nontypeable Haemophilus influenzae from the rat middle ear and lungs as well as from the chinchilla middle ear and nasopharynx. Infection and Immunity 2003;71:4691-99.

[23] Jomaa M, Kyd JM, Cripps AW. Mucosal immunisation with novel Streptococcus pneumoniae protein antigens enhances bacterial clearance in an acute mouse lung infection model. FEMS Immunology \& Medical Microbiology 2005;44(1):59-67.

[24] Dunkley ML, Clancy RL, Cripps AW. A role for CD4+ T cells from orally immunized rats in enhanced clearance of Pseudomonas aeruginosa from the lung. Immunology 1994;83(3):362-9. 
[25] Cripps AW, Dunkley ML, Clancy RL, Kyd JM. Pulmonary immunity to Pseudomonas aeruginosa. Immunology and Cell Biology 1995;73:418-24.

[26] Cripps AW, Dunkley ML, Clancy RL, Kyd JM. Vaccine strategies against Pseudomonas aeruginosa infection in the lung. Behring Inst Mitt 1997;98:262-68.

[27] McClellan SA, Huang X, Barrett RP, van Rooijen N, Hazlett LD. Macrophages restrict Pseudomonas aeruginosa growth, regulate polymorphonuclear neutrophil influx, and balance pro- and anti-inflammatory cytokines in BALB/c mice. Journal of Immunology 2003;170(10):5219-27.

[28] Kernacki KA, Barrett RP, Hobden JA, Hazlett LD. Macrophage inflammatory protein-2 is a mediator of polymorphonuclear neutrophil influx in ocular bacterial infection. Journal of Immunology 2000;164(2):1037-45. [29] Jensen PO, Moser C, Kobayashi O, Hougen HP, Kharazmi A, Hoiby N. Faster activation of polymorphonuclear neutrophils in resistant mice during early innate response to Pseudomonas aeruginosa lung infection. Clinical \& Experimental Immunology 2004;137(3):478-85.

[30] Dean R, Cox J, Bellac C, Doucet A, Starr A, Overweg K. Macrophage-specific metalloelastase (MMP-12) truncates and inactivates ELR+ CXC chemokines and generates CCL2, -7, -8, and -13 antagonists: potential role of the macrophage in terminating polymorphonuclear leukocyte influx. Blood 2008;8(112):3455-64.

[31] Saba S, Soong G, Greenberg S, Prince A. Bacterial stimulation of epithelial G-CSF and GM-CSF expression promotes PMN survival in CF airways. Am J Respir Cell Mol Biol 2002;27:561-67.

[32] Buret A, Dunkley ML, Pang G, Clancy RL, Cripps AW. Pulmonary immunity to Pseudomonas aeruginosa in intestinally immunized rats roles of alveolar macrophages, tumor necrosis factor alpha, and interleukin-1 alpha.

Infection \& Immunity 1994;62(12):5335-43.

[33] Kyd JM, Dunkley ML, Cripps AW. Enhanced respiratory clearance of nontypeable Haemophilus influenzae following mucosal immunization with P6 in a rat model. Infection and Immunity 1995;63:2931-40.

[34] Dunkley ML, Cripps AW, Reinbott PW, Clancy RL. Immunity to respiratory Pseudomonas aeruginosa infection: the role of gut-derived T helper cells and immune serum. In: details JMea-sRNf, editor. Advances in Mucosal Immunology. New York, Plenum Press, 1995: 771-75.

[35] Dunkley ML, Cripps AW, Reinbott PW, Clancy RL. Immunity to respiratory Pseudomonas aeruginosa infection: the role of gut-derived T helper cells and immune serum. Advances in Experimental Medicine \& Biology 1995;371B:771-5.

[36] Dunkley ML, Cripps AW, Clancy RL. Immunity to respiratory Pseudomonas aeruginosa infection: $P$. Aeruginosa-specific T cells arising after intestinal immunization. In: details JMea-sRNf, editor. Advances in Mucosal Immunology. New York, Plenum Press, 1995: 755-59.

[37] Dunkley ML, Rajyagura S, McCue A, Cripps AW, Kyd JM. Pseudomonas aeruginosa-specific IgG1 and IgG2 subclasses in enhancement of pulmonary clearance following passive immunisation in the rat. FEMS Immunol Med Microbiol 2003;1585:37-44. 
Table 1. Concentration of protein antigens purified from P.aeruginosa strain 385 used for IPP and IT immunisation

\begin{tabular}{lccc}
\hline Identification & $\mathbf{N}$ & IPP & IT \\
\hline Pa13 & 6 & $10 \mu \mathrm{g}$ & $5 \mu \mathrm{g}$ \\
Azurin & 6 & $10 \mu \mathrm{g}$ & $5 \mu \mathrm{g}$ \\
ACP & 6 & $10 \mu \mathrm{g}$ & $10 \mu \mathrm{g}$ \\
Amidase & 5 & $5 \mu \mathrm{g}$ & $5 \mu \mathrm{g}$ \\
Aminopeptidase & 5 & $10 \mu \mathrm{g}$ & $5 \mu \mathrm{g}$ \\
KatE & 5 & $5 \mu \mathrm{g}$ & $2 \mu \mathrm{g}$ \\
KatA & 5 & $10 \mu \mathrm{g}$ & $10 \mu \mathrm{g}$ \\
\hline
\end{tabular}


Table 2. Phagocytic cell counts in BAL fluid of rats immunized with protein antigens, four hours post-pulmonary challenge with live P.aeruginosa strain 385.

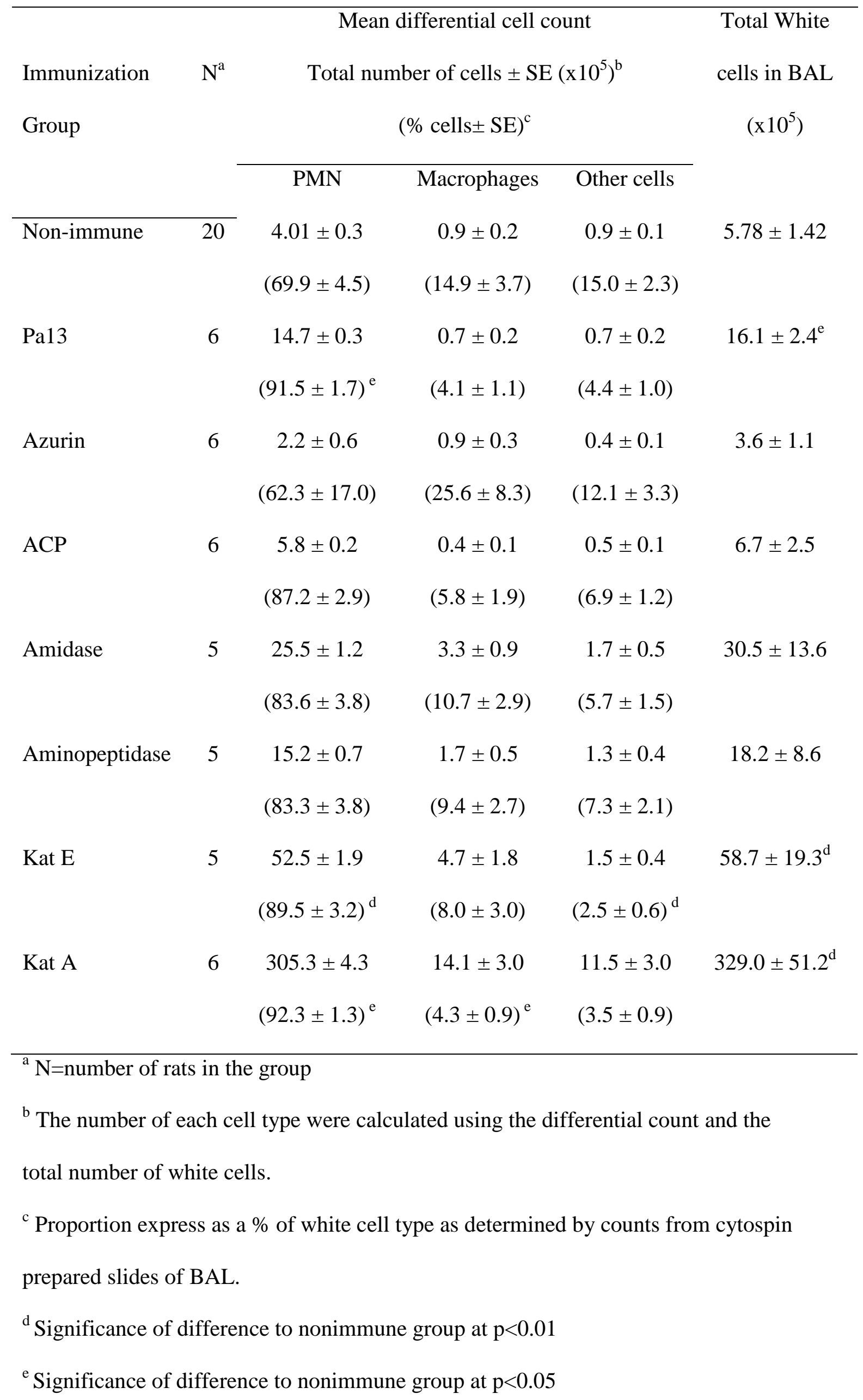



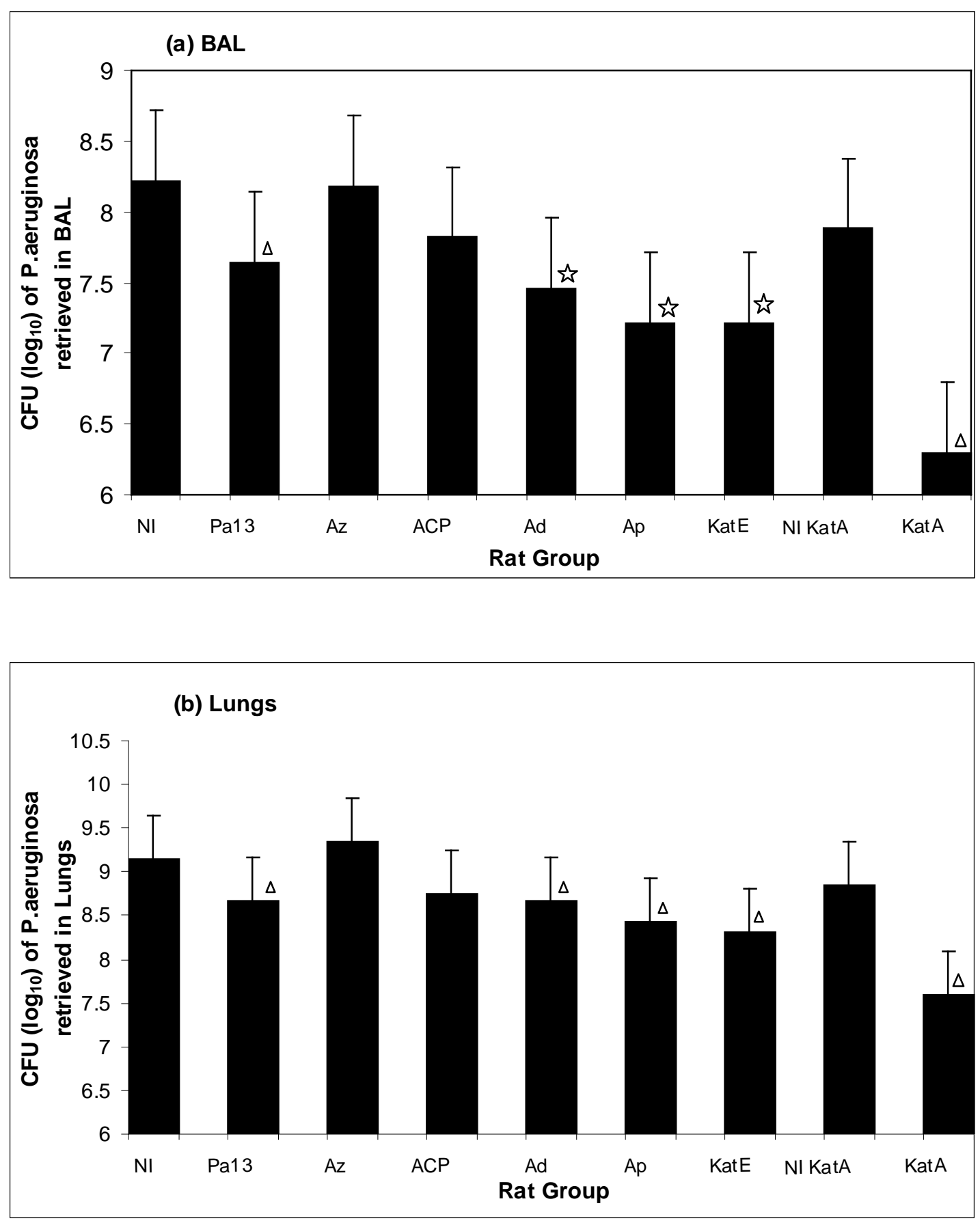

Figure 1 

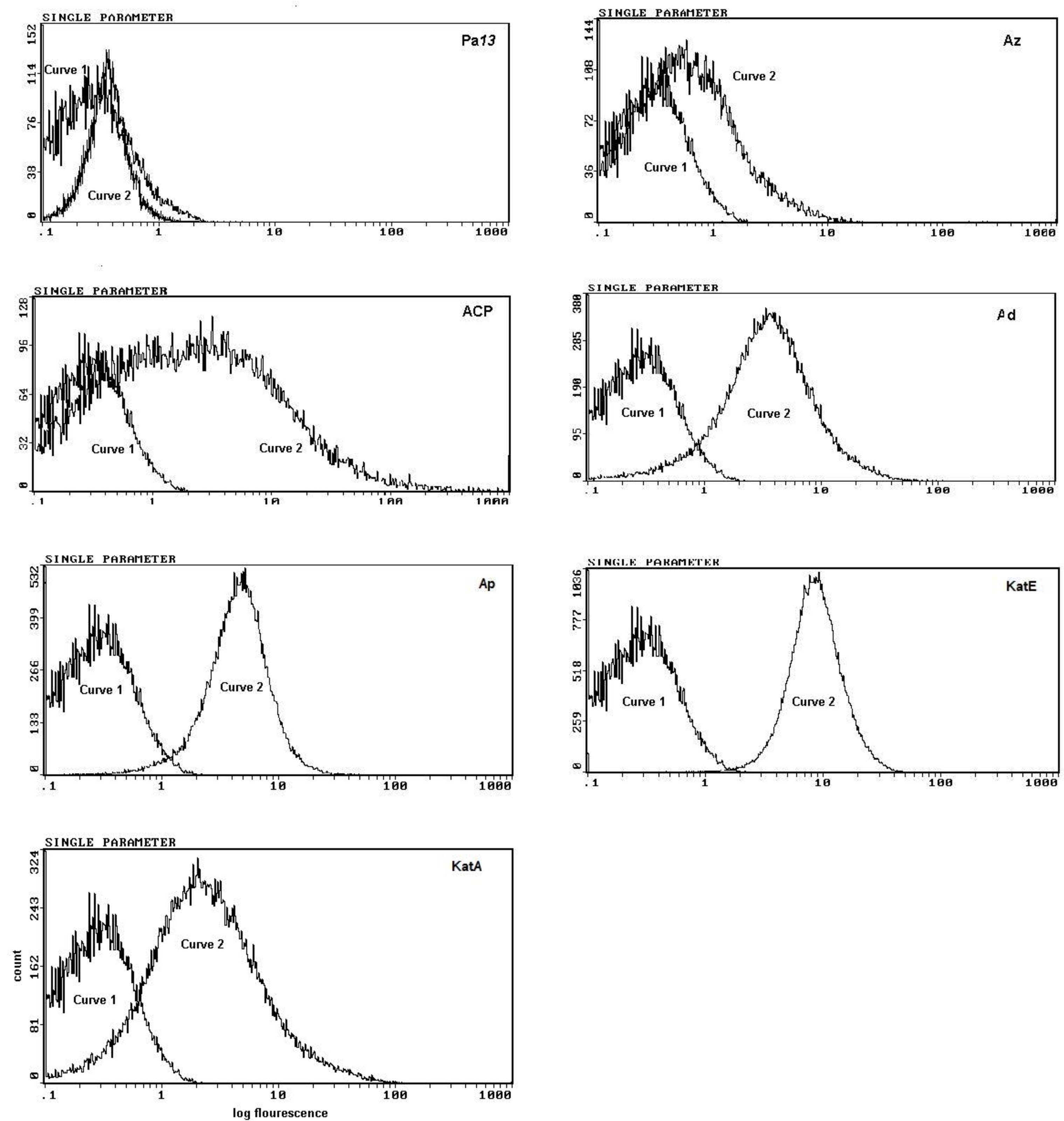


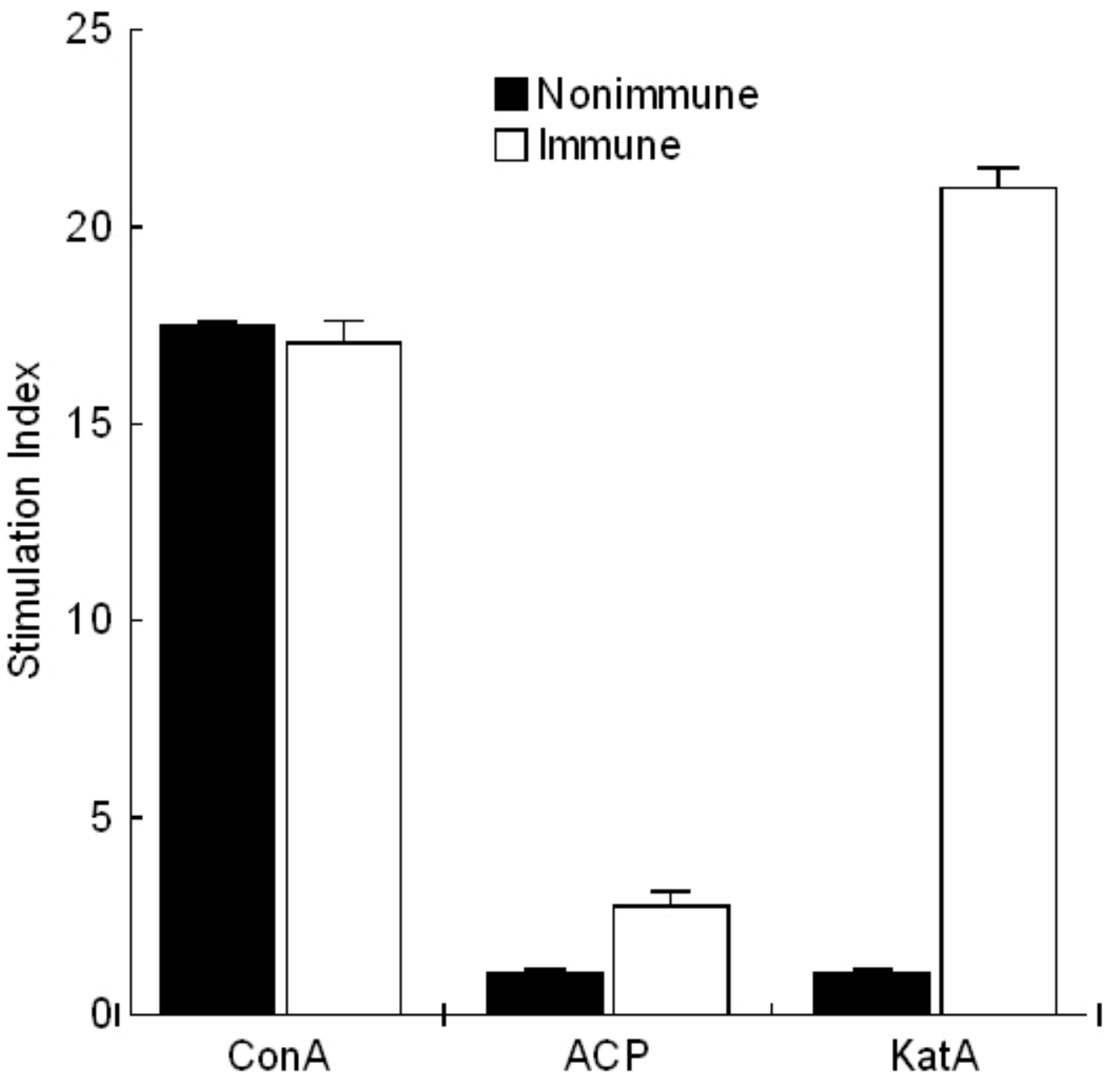

